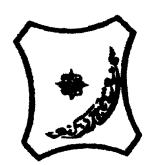

Bayero Journal of Pure and Applied Sciences, 10(1): 210 - 214

Received: April, 2017

Accepted: June, 2017

ISSN $2006-6996$

\title{
THE EFFECT OF RUTIN ON LIPID PROFILE AND LIVER FUNCTION ENZYMES ON ALLOXAN INDUCED HYPERGLYCAEMIC WISTAR RATS.
}

\author{
${ }^{* 1}$ Tanko, Y., ${ }^{1}$ Jimoh, A., ${ }^{1}$ Sulaiman, I., ${ }^{2}$ Mohammed, K.A., ${ }^{3}$ Salisu, A.I, ${ }^{4}$ Yusuf, R. and \\ ${ }^{5}$ Musa, S.A. \\ ${ }^{1}$ Department of Human Physiology, Ahmadu Bello University, Zaria, Nigeria \\ ${ }^{2}$ Department of Human Physiology, Kaduna State University, Nigeria \\ ${ }^{3}$ Department of Human Physiology, Bayero University, Kano.Nigeria \\ ${ }^{4}$ Department of Chemical Pathology, Ahmadu Bello University, Zaria, Nigeria \\ ${ }^{5}$ Department of Human Physiology, Bayero University, Kano.Nigeria \\ *Corresponding author: yusuftanko@abu.edu.ng Tel: +2348037054274
}

\begin{abstract}
The aim of this research was to investigate the effects of rutin on lipid profile and liver function enzymes on alloxan induced hyperglycaemia in Wistar rats. Hyperglycaemic was induced by intraperitoneal injection of $150 \mathrm{mg} / \mathrm{kg}$ alloxan monohydrate. The rats were grouped into five groups of five rats each. Group 1 served as the diabetic negative control, Group 2 served as positive control and was treated with $2 \mathrm{mg} / \mathrm{kg}$ glibenclamide, while Groups 3, 4 and 5 were treated with 50, 100 and $200 \mathrm{mg} / \mathrm{kg}$ body weight of rutin respectively. Rutin was administered to the animals orally for a period of four weeks. At the end of the experimental period, the rats from each experimental group were sacrificed using light chloroform and sera were collected for the determination of lipid profile and liver function enzymes. There was a significant $(p<0.05)$ decreased in the total cholesterol, triglyceride and low density lipoprotein as compared to control. However, there was a significant $(p<0.05)$ increased in the level of high density lipoprotein when compared to diabetic control. Furthermore, there was a significant $(p<0.05)$ decreased in the serum liver enzymes; Aspartate transaminase (AST) Alanine transaminase (ALT) and Alkaline phosphates (ALP) as compared to control. As regards to the reference drug $2 \mathrm{mg} / \mathrm{kg}$ glibenclamide there was a significant $(p<0.05)$ increased in the liver enzymes function as compared to control. Conclusion, rutin has hypolipidemic effect and also decreased liver function enzymes activity on alloxan induced hyperglycaemic rats.
\end{abstract}

Keywords; Rutin, Hyperglycaemia, Alloxan, Lipid profile, Liver enzymes

\section{INTRODUCTION}

Diabetes is a common metabolic disorder characterized by hyperglycemia due to an absolute or relative insulin deficiency (Lawal et al., 2008; WHO, 2010). It affects essential biochemical pathways of the body including carbohydrate, protein, and lipid metabolisms. The World Health Organization (WHO), estimated that there were 171 million people in the world with diabetes in the year 2008 and this is projected to increase by over a $100 \%$ to 366 million by 2030 (WHO, 2010). Diabetic-induced hyperlipidemia is attributable to excess mobilization fat from the adipose due to under utilization of glucose ( Nimenibo-uadia, 2003). Diabetes also associated with reduced life expectancy, significant high mortality and diminished quality of life. In 2005 an estimated 1.1 million people died from diabetes and diabetes complications (WHO, 2008). Serum enzymes measurements are valuable tool in clinical diagnosis that provides information on the effect and nature of pathological damage to any tissue (Daisy and Saipriya, 2012). AST, ALT and ALP are biomarkers of damage to the plasma membrane and endoplasmic reticulum and are often used to assess the integrity of the plasma membrane and tissues after being exposed to certain pharmacological agents
(Rathod et al., 2009). Lipid profile is a group of blood tests which are carried out to determine the risk of coronary artery diseases (CAD). Hyperlipidaemia, a risk factor of cardiovascular diseases is frequently seen among diabetic patients (Mengesha, 2006). Serum lipid levels are commonly increased in diabetes mellitus and such an elevation represents a risk factor for coronary heart disease ( Muthulingam, 2010). Rutin is abundantly present in onions, apples, tea and red wine (Hertog et al. 1993). Rutin exhibits multiple pharmacological activities including antibacterial, antitumour, antiinflammatory, antidiarrhoeal, antiulcer, antimutagenic, myocardial protecting, vasodilator, immunomodulator and hepatoprotective activities (Janbaz et al. 2002). Much interest has gathered in the role and usage of natural antioxidants as a means to prevent oxidative damage in diabetes with high oxidative stress. Flavonoids represent the most common and widely distributed group of plant phenolics (Harborne 1986) and are abundant in foods. Quercetin (3,30,40,5,7-pentahydroxy flavone) is one of the most common native flavonoids occurring mainly in glycosidic forms such as rutin $(5,7,30,40-$ $\mathrm{OH}$, 3-rutinose) (fig. 2) (Havsteen 1983). Quercetin and rutin are the flavonoids most abundantly consumed in foods (Nakamura et al. 2000). 
Bajopas Volume 10 Number 1 June, 2017

Rutin is a citrus flavonoid glycoside found in wheat (Kreft et al., 1999). It is also found in the fruit of the favadanta tree, fruit and flowers of the pagoda tree, fruit and fruit rinds (especially the citrus fruits, orange, grapefruit, lemon and lime) and apple; berries such as mulberry, ash tree fruits and cranberries. Rutin is one of the primary flavonoids which are ingredients of numerous multivitamin preparations and herbal remedies. It has some established pharmacological effects due to its antioxidant and anti-inflammatory properties, and cytoprotective actions connected with anti-ageing and anti-cancer properties (La Casa et al., 2000). Rutin scavenges free radicals and inhibits superoxide radical production as well as enhance the activity of antioxidant enzymes, glutathione peroxidase and reductase to maintain the levels of the reduced glutathione, which is a biological antioxidant (Kamalakkannan et al., 2006). The aim of this study is to determine the effect of Rutin on lipid profile and liver function enzymes on alloxan induced hyperglycaemic in Wistar rats.

\section{MATERIALS AND METHODS}

\section{Chemicals / drugs used}

Glibenclamide and alloxan were purchased from Sigma chemical Company St. Louis U.S.A. Rutin was purchased from Sigma Aldrich Germany (BN-12358M3)

\section{Experimental animals}

Twenty five (25) Wistar rats of both sexes (120-150 g) were obtained from the Animal House of the Department of Human Physiology, Ahmadu Bello University, Zaria, Nigeria. The rats were maintained on standard laboratory animal feed and water ad libitum, and housed in polypropylene cages at room temperature throughout the study. The animals were maintained on standard small animal feeds (Excel feed, Ilorin, Nigeria).

\section{Induction of Hyperglycaemia}

Wistar rats were fasted for about 16-18 $h$, after which hyperglycamia was induced by a single intraperitoneal injection of Alloxan monohydrate dissolved in $0.9 \%$ cold normal saline solution at a

dose of $150 \mathrm{mg} / \mathrm{kg}$ body weight (Katsumata et al., 1999). Alloxan produces fatal hypoglycaemia and to prevent this, the rats were treated with $20 \%$ glucose solution orally for 6 hours. After which they were placed on $5 \%$ glucose solution for 24 hours (Dhandapani et al., 2002). Blood was collected from the tail vein of the rats after 72 hours of Alloxan injection. The rats having fasting blood glucose level greater than or equal to $200 \mathrm{mg} / \mathrm{dl}$ were selected for the study.

\section{Determination of Fasting blood glucose levels}

Fasting blood glucose levels were determined by using the glucose oxidase method (Trinder, 1969) with ONE TOUCH BASIC ${ }^{\circledR}$ Glucometer (LIFESCAN, Inc 2001 Milpitas, CA 95035, USA) and results were reported as mg/dl (Rheney and Kirk, 2000).

\section{Experimental Design}

In the experiment, a total of twenty five (25) Wistar rats were used; the animals were randomly divided into six groups of five rats each as follows:

Groups 1: Hyperglycaemic control and administered $(0.5 \mathrm{ml} / \mathrm{kg}$ body weight) distilled water
Group 2: Hyperglycaemic administered glibenclamide $2 \mathrm{mg} / \mathrm{kg}$ body weight for 28 days orally

Group 3: Hyperglycaemic and treated with Rutin $50 \mathrm{mg} / \mathrm{kg}$ body weight for 28 days orally.

Group 4: Hyperglycaemic treated with Rutin 100 $\mathrm{mg} / \mathrm{kg}$ body weight for 28 days orally.

Group 5: Hyperglycaemic treated with Rutin 200 $\mathrm{mg} / \mathrm{kg}$ body weight for 28 days orally

Determination of Blood Glucose Level

Blood glucose level was determined by collection of blood sample from the tail artery of the rats by glucose-oxidase principle (Beach and Turner, 1958) using digital glucometer (Accu-chek Advantage) and was expressed as $\mathrm{mg} / \mathrm{dL}$. Rat with blood glucose levels $200 \mathrm{mg} / \mathrm{dl}$ were considered for the study.

Blood Sample Collection and Serum Preparation After the treatment all animals were sacrificed using light chloroform and $5 \mathrm{~mL}$ of blood sample were collected into specimen bottles and allowed to clot and separated by centrifugation at $3,000 \mathrm{~g}$ for 10 minutes using Centrifuge Hitachi (Universal 32). The supernatant obtained were used for the determination of lipid profile and liver enzymes.

Determination of serum liver enzymes activities

Activities of serum alanine aminotransaminase was estimated by the method of Tietz (1995), aspartate aminotransaminase was determined by the method of Henderson and Moss (2001) while alkaline phosphatase was determined according to the method of Scherwin (2003). All the above were done using ELITECH Clinical Systems kits.

\section{Determination of Lipid Profile}

\section{Determination of Serum Total Cholesterol}

This was determined spectrophotometrically, using enzymatic colometric assay kits (Randox Laboratories Limited kits, Unite Kingdom) as follows: The serum level of total cholesterol was quantified after enzymatic hydrolysis and oxidation of the sample as described by the method of Stein (1987). $1000 \mu \mathrm{L}$ of the reagent was added to each of the sample and standard. This was incubated for 10 minutes at 20-25 ${ }^{0} \mathrm{C}$ after mixing and the absorbance of the sample ( $A$ sample) and standard ( $\left.A_{\text {standard }}\right)$ was measured against the reagent blank within 30 minutes at $546 \mathrm{~nm}$. The absorbance is expressed in $\mathrm{mmol} / \mathrm{L}$.

\section{Determination of Serum Triglyceride}

The serum triglyceride level was determined after enzymatic hydrolysis of the sample with lipases as described by the method of Tietz (1990). $1000 \mu \mathrm{L}$ of the reagent was added to each of the sample and standard. This was then incubated for 10 minutes at 20-25 ${ }^{\circ} \mathrm{C}$ after mixing and the absorbance of the sample $\left(A_{\text {sample }}\right)$ and standard $\left(A_{\text {standard }}\right)$ was measured against the reagent blank within 30 minutes at 546 $\mathrm{nm}$. The value was expressed in $\mathrm{mmol} / \mathrm{L}$.

\section{Determination of Serum High-density Lipoprotein cholesterol}

The serum level of HDL-C was measured by the method of Wacnic and Albers (1978). Low-density lipoproteins (LDL and VLDL) and chylomicron fractions in the sample was precipitated quantitatively by addition of phosphotungstic acid in the presence of magnesium ions. 
Bajopas Volume 10 Number 1 June, 2017

The mixture was allowed to stand for 10 minutes at room temperature and centrifuged for 10 minutes at $2000 \mathrm{~g}$. The supernatant represented the HDL-C fraction. The cholesterol concentration in the HDL fraction, which remained in the supernatant, was determined. The value was expressed in $\mathrm{mmol} / \mathrm{L}$.

Determination of Serum Low-density Lipoprotein cholesterol ( $L D L-C)$

The serum level of (LDL-C) was measured according to the protocol of Friedewald et al. (1972) using the relationship below:

LDL cholesterol

$=\frac{[\text { Total cholesterol }]-[\text { HDL cholesterol }]-\text { Triglyceride }}{2.2}$

The value was expressed in $\mathrm{mmol} / \mathrm{L}$.

\section{Statistical Analysis}

Data obtained from each group were expressed as mean \pm SEM. The data were statistically analyzed using (ANOVA) with Tukey's post-hoc test to compare the levels of significant between the control and experimental groups. All statistical analyzed were done using SPSS version 17.0 software and Microsoft Excel (2007). The values of $p \leq 0.05$ were considered significant.

\section{RESULTS}

Effects of Rutin on Serum Lipid Profile:

Administration of the three doses of rutin 50,100 and $200 \mathrm{mg} / \mathrm{kg}$ significantly decreased $(p<0.05)$ the serum levels of total cholesterol, triglyceride, low density lipoprotein when compared to hyperglycaemic control. Also in relation to high density lipoprotein, there was a significant $(p<0.05)$ increased as compared to the hyperglycarmic control. However, when compared to the standard drug $2 \mathrm{mg} / \mathrm{kg}$ glibenclamide there was a significant $(p<0.05)$ decreased in the total cholesterol, triglyceride and low density lipoprotein, while there was an increase in the high density lipoprotein as compared to hyperglycaemic control as shown in table 1.

Effects of Rutin on Serum Liver Function Enzymes :

Administration of the three doses of rutin 50,100 and $200 \mathrm{mg} / \mathrm{kg}$ significantly decreased $(p<0.05)$ the serum liver enzymes function aspartate transaminase, alanine transaminase and alkaline phosphatase as compared to hyperglycaemic control. However, when compared to the standard drug $2 \mathrm{mg} / \mathrm{kg}$ glibenclamide there was a significant $(p<0.05)$ decreased serum liver enzymes as compared to hyperglycaemic control as shown in table 2 .

Table 1: Effects of Rutin on Serum Lipid Profile on Alloxan induced Hyperglycaemic Wistar Rats

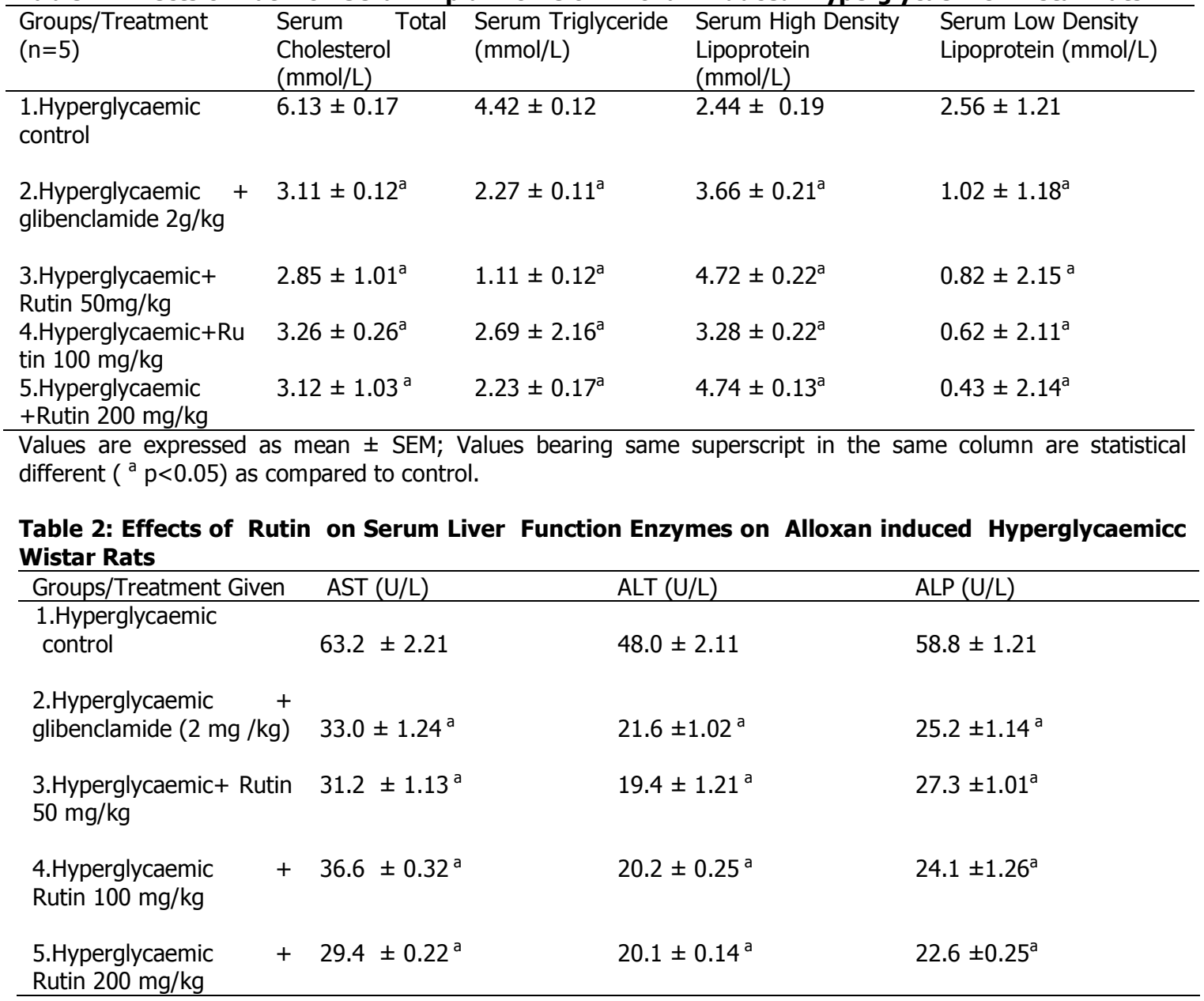

Values are expressed as mean \pm SEM; Values are expressed as mean \pm SEM; Values bearing same superscript in the same column are statistical different as compared to control( $\left.{ }^{a} p<0.05\right)$ 


\section{DISCUSSION}

The present study showed that administration of rutin at the tested doses of 50100 and $200 \mathrm{mg} / \mathrm{kg}$ significantly decreased the levels of Total cholesterol, Triglyceride, Low density lipoprotein and increased High density lipoprotein in diabetic when compared with the diabetics control as shown in table 1. The marked hyperlipidemia that characterizes the diabetic state may therefore be regarded as a consequence of unlimited actions of lipolytic hormones on the fat depots (Ayeleso et al., 2012). Lowering of serum lipid levels through dietary or drugs therapy seems to be associated with a decrease in the risk of vascular disease in diabetes (Ayeleso et al., 2012). The results of the present investigation showed that three doses $(50,100$ and $200 \mathrm{mg} / \mathrm{kg})$ of rutin administered to diabetic rats produced a significant decreased $(p<0.05)$ on total cholesterol, triglyceride, low density lipoprotein and significant $(p<0.05)$ increased in high density lipoprotein as compared to control as shown in table 1 . This observed improvement in the lipid profile status of diabetic treated rats revealed the cardio-protective properties of rutin. James et al. (2010) had reported that about $30 \%$ of blood cholesterol is carried in the form of HDL-C. HDL-C function to remove cholesterol atheroma within arteries and transport it back to the liver for its excretion or reutilization, thus high level of HDL-C protect against cardiovascular disease. Therefore, the observed increased in the serum HDL$C$ level on administration of various doses of rutin to hyperglycaemic rats indicates that rutin has HDL-C boosting effect.

Furthermore, result obtained in the present study on the liver enzymes showed that the activities of serum liver enzymes; aspartate transaminase (AST), alanine transaminase (ALT) and alkaline phosphates (ALP) were significantly increased in the diabetic untreated

\section{REFERENCES}

Abolfathi, A.A., Mohajeri, D., Rezaie, A. and Nazeri, M. (2012). Protective effects of green tea extract against hepatic tissue injury in streptozotocin-induced diabetic rats. EvidenceBased Complementary and Alternative Medicine, vol, 201210 pages.

Ayeleso, A.O. Oguntibeju, O.O. and Brooks, N.L. (2012). Effects of dietary intake of red palmoil on lipid profile and fatty acid composition in male Wistar rats. African Journal ofBiotechnology, 11(33): 8275-8279

Beach, E.F. and Turner, J.J. (1958). An enzymatic method for glucose determination uptake inbody fluids. Clinical Chemistry, 4: 462-468.

Concepción, N. M., Pilar, M. M., Martín, A., Jiménez, J. and Pilar U. M. (1993). Free radicalscavenger and antihepatotoxic activity of Rosmarinus tomentosus. Planta Medica, 59: 312314.

Daisy, P. and Saipriya, K. (2012). Biochemical analysis of Cassia fistula aqueous extract and phytochemically synthesized gold nanoparticles as hypoglycemic treatment for diabetesmellitus. International Journal of Nanomedicine, 7: 1189-1202. group. However, administration of the rutin significantly $(p<0.05)$ decreased the activities of liver enzymes aspartate transaminase (AST), alanine transaminase (ALT) and alkaline phosphates (ALP) when compared with diabetic control when administered various doses of rutin as shown in table 2. Increased gluconeogenesis and ketogenesis might be due to an elevated activity of transaminase (Gandhi et al., 2011). Abolfathi et al. (2012) reported that the elevation in markers of liver injury such as ALT, AST and ALP indicate hepatocyte damage in experimental diabetes. And this increase in the activities of these enzymes in diabetes may be as a result of leaking out of these enzymes from the tissue into the blood stream (Concepción et al., 1993). AST and ALT are released when injury involves organelles such as the mitochondria (Kumar et al., 2003). The ability of rutin to decreased the serum levels of Alanine treansaminase, Aspartate transaminase and Alkaline Phosphatase serum activities suggest its hepato-cellular protective function and this can be to its attributed to antioxidant properties. Conclusion rutin has hypolipidemic effect and reduced the activity of liver function enzymes on alloxan induced hyperglycaemic rats.

\section{Authors' contributions}

This work was carried out in collaboration between all authors. Authors TY designed the study, wrote the protocol, YR and MKA wrote the first draft of the manuscript. Authors SAI and SI managed the literature search; Author MSA managed the statistical analysis of the study. Author JA managed the experimental process. All authors read and approved the final manuscript.

\section{Conflict of Interests}

Authors have declared that no conflict of interests exists.

Dhandapani S, Ramasamy, SV, Rajagopal, S Namasivayam, N( 2002). Hypolipidemic effect of Cuminum cyminum L. on alloxaninduced diabetic rats. Pharmacol. Res, 46 (3): 251-255.

Friedewald, W. T., Levy, R. and Fradrickson, D. S. (1972). Estimation of concentration of Low density lipoprotein cholesterol in plasma without the use of preparative ultracentrifugation. Clinical Chemistry.19: 449-452.

Gandhi, G.R., Ignacimuthu, S. and Paulraj, M.G. (2011). Solanum torvum Swartz. Fruitcontaining phenolic compounds shows antidiabetic and antioxidant effects in streptozotocin induced diabetic rats. Food and Chemical Toxicology, 49(11): 27252733.

Harborne, J. B(1986): Plant phenolics In: Encyclopedia of plant physiology, Vol. 8. Secondary plant products. Eds.: E. A. Bell \& B. V. Charlwood. Springer Verlag, Berlin, , pp. 329-395.

Havsteen, B.(1983) : Flavonoids, a class of natural products of high pharmacological potency. Biochem. Pharmacol. , 32, 1141-1148 
Henderson, A. R., and Moss, D. W. (2001). Enzymes Tietz Fundamentals of Clinical Chemistry, $5^{\text {th }}$ Ed., Buritis, C. A. and Ashwood, E. R. (W.B. Saunders eds. Philadelphia (USA).Pp. 352.

Hertog, M. G., Hollman, P.C, . Katan M.B and Kromhout D (1993): Intake of potentially anticarcinogenic flavonoids and their determinants in adults in The Netherlands. Nutr. Cancer 1, 20, 21-29.

James, D. B., Owolabi, O. A., Ibrahim, A. B., Folorunsho, D. F., Bwalla, I. and Akanta, F. (2010). Changes in lipid profile of aqueous and ethanolic extract of Blighia sapida in rats. Asian journal of Medical Sciences, 2(4): 177- 180.

Janbaz, K. H., S. A. Saeed and A. H. Gilani (2002) : Protective effect of rutin on paracetamoland $\mathrm{CCl} 4$-induced hepatotoxicity in rodents. Fitoterapia, 73, 557-563.

Kamalakkanan, N., M. Rajadurai and P. Stanely Mainzen Prince(2003) : Effect of Aegle marmelos fruits on normal and streptozotocin diabetic Wistar rats. J. Med. Food, 6, 93-98.

Katsumata, KY, Katsumata, TO and Katsumata, $T(1999)$. Potentiating effects of combined usage of three sulfonylurea drugs on the occurrence of alloxan-induced diabetes in rats. Horm Metab Res, 25: 125-126.

Kreft, S., Knapp, M. and Kreft. (1999). Extraction of rutin from buckwheat seeds and determination by capillary electrophoresis. Journal of Agricultural Food Chemistry, 4 (11), 46-52.

Kumar, R. S., Manickam, P., Periyasamy, V. and Namasivayam, N.(2003). Activity of Cassiaauriculata leaf extract in rats with alcoholic liver injury. Journal of NutrionalBiochemistry, 14: 452-458.

La Casa, C., Villegas, I., Alar Con de la lastra, C., Mutilua, N. and Martin Calero, M.J. (2000). Evidence for protective and antioxidant properties of rutin, a natural flavones against ethanol induced gastric lesions. Journal of Ethno pharmacology, 71, 45-53.

Lawal, H.A., Atiku, M.K., Khelpai, D.G. and Wannag, N.N. (2008). Hypoglycaemic and hypolipidaemic effects of the aqueous leaf extract of Murraya koenigii in normal and alloxan induced diabetic rats. Nigerian Journal of Physiological Sciences, 23(1-2): 37-40

Mengesha, A.Y. (2006). Lipid profile among diabetes patients in Gaborone, Botswana. Journalof Endocrinology, Metabolism and Diabetes of South Africa, 11(1): 32-34.
Muthulingam, M. 2010. Antidiabetic efficacy of leaf extracts of Asteracaniha longifolia (Linn.)Nees. on alloxan induced diabetics in male albino Wistar rats. International Journal ofPharmaceutical and Biomedical Research, 1(2): 28-34.

Nakamura, Y., S. Ishimitsu and Y. Tonogai (2000) : Effects of quercetin and rutin on serum and hepatic lipid concentrations, fecal steroid excretion and serum antioxidant properties. J. Health Sci. , 46, 229-240.

Nimenibo-uadia, R. (2003). Effect of aqueous extract of Canavalia ensiformis seeds onhyperlipidemic and hyperkotonaemia in alloxan-induced diabeticrats.Biokemistri, 157-15.

Rathod, N.R., Raghuveer, I., Chitme, H.R. and Chandra, R. (2009). Free radical scavengingactivity of Calotropis gigantea on streptozotocin-induced diabetic rats. Indian Journal of Pharmaceutical Sciences, 71: 615621.

Scherwin, J. E. (2003). Liver function. Clinical Chemistry: Theory Analysis Correction, $4^{\text {th }}$ Ed.,Kaplan, L. A., Pesce, A. J., Kazmierczak, S. C., (Mosby Inc. Eds., St Louis USA), Pp.492 and appendix.

Stein, E. A. (1987). Lipids, lipoproteins and Apolipoproteins. In: Treitz, N. W. (Ed). Fundamentals of Clinical Chemistry. 3rd Edn., W . B Sauders Philadelphia, Pp. 470479.

Tietz, N.W. (1990). Clinical Guide to Laboratory Test, Second Edition W.B. Saunders Company, Philadelphia, U.S.A. Pp. 554-556.

Tietz, N. W. (1995). Clinical guide to laboratory tests, $3^{\text {rd }}$ Ed., (W.B. Saunders eds. Philadelphia USA), Pp.76.

Trinder, P. (1969). Annals of Clinical Biochemistry: 6:24: Quoted in Cheesbrough, M. (1992) Medical Laboratory Manual for Tropical Countries. Vol. 1 (2nd Edition). ELBS, Cambridge. 527-545.

Wacnic, R. G. and Alber, J. J. (1978). A comprehensive evaluation of the heparin manganese precipitation procedure for estimating high density lipoprotein cholestsrol. Journal of Lipid Research, 19: 65-76.

World Health Organization (2008). WHO Study Group of prevention of Diabetes Mellitus. WHO Technical Science, 844:11.

World Health Organization (2010). Diabetes mellitus report of a WHO study Group, 